\title{
NOVEL POLYDIOXANONE - PLURONIC 127 OXYTOCIN IMPREGNATED MESH, PRELIMINARY STUDY OF OXYTOCIN RELEASE IN VITRO
}

\author{
ANDREEA ELENA MIRON (LUNGU) ${ }^{a}$, MARIOARA MOLDOVAN ${ }^{b}$, \\ DOINA PRODAN ${ }^{\mathrm{b}}$, MIHAELA VLASSA $^{* \mathrm{~b}}$, MĂDĂLINA MOLDOVAN ${ }^{\mathrm{c}}$, \\ RAREȘ CĂLIN ROMAN", MÎNDRA EUGENIA BADEA ${ }^{a}$
}

\begin{abstract}
Polymers represent a novel alternative in bone regeneration. Polydioxanone combined with Pluronic was used as a carrier for Oxytocin in form of an interfacial deposition obtained scaffold. The low rate of resorption of the scaffold follow the bone regeneration sequence assuring a constant and continuous release of Oxytocin. The Oxytocin release was monitored by RP-HPLC method. The separation was performed on a Phenomenex Luna $5 \mu \mathrm{m}$ C18 100A, 250x4.6mm, using isocratic elution with acetonitrile: phosphate buffer $\mathrm{pH} 7(30: 70 \mathrm{v} / \mathrm{v})$ mobile phase. Flow rate $1 \mathrm{ml} / \mathrm{min}$, column temperature $30^{\circ} \mathrm{C}, \mathrm{DAD}, \lambda=220 \mathrm{~nm}$. The surface morphology of polydioxanone - pluronic 127 - Oxytocin impregnated mesh was characterized by SEM.

The preliminary results show that the Polydioxanone combined with Pluronic is a promising polymer for bone regeneration engineering.
\end{abstract}

Keywords: polydioxanone, Oxytocin, bone reconstruction, biodegradable scaffolds, RP-HPLC, SEM

\section{INTRODUCTION}

First used as monofilament suture material, polydioxanone is a hydrophobic instable polymer with a low resorption rate expanding between 6 months to 2 years [1]. It can be manufactured as meshes, solid implants or membranes, making it suitable as a biological substitute [2]. Recently studied

a University of Medicine and Farmacy luliu Hațieganu, Dental Medicine Department of Prevention in Dental Medicine, 31 Avram lancu str., RO-400083, Cluj-Napoca, Romania

' Babeş-Bolyai University „Raluca Ripan” Institute for Researh in Chemistry, 30 Fântânele str., RO-400294, Cluj-Napoca, Romania

c University of Medicine and Farmacy Iuliu Hațieganu, Dental Medicine Department of CranioMaxilo-Facial Surgery, 33 Calea Moților str., RO-400001, Cluj-Napoca, Romania

*Corresponding author mihaela.vlassa@ubbcluj.ro 
in chest wall defects reconstruction, polydioxanone proved to sustain the needed resistance, flexural strength, and biocompatibility for a bone implant [3]. In large reconstructions of defects that extend the $6 \mathrm{~cm}$ limit of natural healing, the implant integration encounters several complications. Situs infection is the most common adverse outcome, followed by the pathological movement of the reconstructive segments, and abnormal scar tissue formation [4].

Absorbable graft materials present fewer healing complications when properly covered with soft tissue. In this context, adding Pluronic 127 to the polydioxanone mesh enriches the final compound hydrophilic behavior assuring a greater resorbable potency by hydrolysis [5]. Because of Pluronic 127 high hydrophilicity that compound was successfully used as cell carrier system in bone regeneration, maintaining cell viability and assuring the necessary permeability for bone growth mediators to reach the carried cells [6-9]. Pluronic 127 (poloxamer 407) is a synthetic hydrogel made of amphiphilic copolymers consisting of units of ethylene oxide (PEO) and polypropylene oxide (PPO) [9]. Due to its thermosensitivity it changes from solution to gel state at $37^{\circ} \mathrm{C}$ enabling the carrying matrix to withhold its charge stable in the bone defect [10].

Combining a slow resorbable polymer with a very fast one (small traces of pluronic were found after 3 weeks from its insertion in a bone defect) results in a controlled compound with superior mechanical strength and biocompatibility which may be used as a delivery system for cells, chemical mediators, proteins, growth factors, hormones, and drugs in bone tissue engineering.

Oxytocin is a hypophyseal hormone which plays an important role in labor, lactation and social relationships. Also, its role as a bone anabolic hormone is well known, local administration was yet avoided giving its short half-life and its lack of resistance to hydrolytic enzymes. Creating the optimal condition for Oxytocin release acquires a stable hydrophilic carrier with the right resistance, biodegradable rate and chemical bonds that allows Oxytocin to reach the bone tissue gradually, according to its healing sessions [11].

Oxytocin reaches osteoblast receptors and signals them to the bone defect stimulating new bone formation [12]. Its catabolic effect on adipocytes prevents enlargement of the fatty bone marrow, promoting dense trabecular bone with reduced marrow space. Oxytocin inhibits osteoclastic activity [13]. Oxytocin's osteoinductivity combined with its carrier polydioxanone-pluronic high biocompatibility and volumetric stability, assures the premises for optimal bone regeneration.

A wide range of analytical methods have been used to determine Oxytocin in different matrices. Radioimmunoassay (RIA) and Enzyme immunoassay (ELISA) was used to quantitative measurement of Oxytocin in biological sample because of its high sensitivity [14]. The chromatographic 
NOVEL POLYDIOXANONE - PLURONIC 127 OXYTOCIN IMPREGNATED MESH, PRELIMINARY STUDY OF OXYTOCIN RELEASE IN VITRO

methods were also used for determination of the Oxytocin in biological matrix by high performance liquid chromatography technique with different detectors (HPLC-UV) [15, 16], and LC plus tandem mass spectrometry (MS/MS) [17, - 20].

The aim of the work was to obtain the polymeric matrix (the mesh) for the Oxytocin impregnation and to monitor the release of this hormone by the HPLC technique. Also, the structure of polymeric mesh morphology was studied by SEM.

\section{RESULTS AND DISCUSSION}

For the quantitative determination of Oxytocin (see Figure 1) released from the polymeric mesh, a liquid chromatographic RP-HPLC method with isocratic elution was used. The validation of the present analytical method was done by the following parameters: selectivity, linearity, LOD (limit of detection), LOQ (limit of quantification) and precision [21].

Selectivity represent the ability to measure unequivocally the desired analyte in the presence of components such as excipients and impurities that may also be expected to be present. Thus, the selectivity was established by comparing the chromatogram of the Oxytocin standard solution with those of an Oxytocin sample extract (Figure 2). The retention time of Oxytocin were at 4.372 min both in standard solution and sample extract.

Linearity indicates the ability to obtain results that are directly proportional to the concentration of the analyte in samples and was established by plotting the analyte peak area against the analyte concentration. The obtained results proved an $\mathrm{R}^{2}$ (correlation coefficient) of 0.9998 (Table 1).

Precision is the degree of agreement among individual results. The intra-day and inter-day precision were expressed as percentage of relative standard deviation (\% RSD).

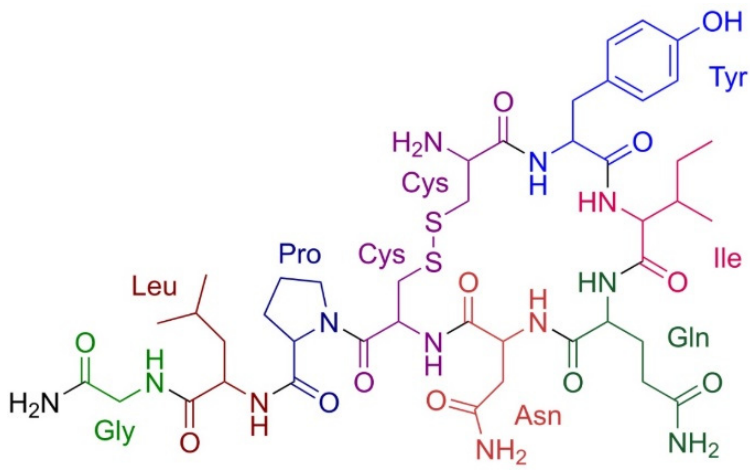

Figure 1. Chemical structure of the Oxytocin 
ANDREEA ELENA MIRON (LUNGU), MARIOARA MOLDOVAN, DOINA PRODAN, MIHAELA VLASSA, MĂDĂLINA MOLDOVAN, RAREȘ CĂLIN ROMAN, MÎNDRA EUGENIA BADEA

The obtained results, $0.62 \mu \mathrm{g} \mathrm{mL}^{-1}$ value of LOD and $1.89 \mu \mathrm{g} \mathrm{mL}-1$ for LOQ respectively, for Oxytocin determination, indicate a good sensitivity of the proposed method.

The parameters of the calibration curve are shown in Table 1 and the RP-HPLC chromatograms are presented in Figure 2.

Table 1. Linear regression data, LOD and LOQ of the Oxytocin standard solution

\begin{tabular}{|c|c|}
\hline Parameters & Oxytocin \\
\hline${ }^{a} \mathrm{RT}[\mathrm{min}]$ & 4.37 \\
\hline${ }^{\mathrm{b}}$ Regression coefficient $\mathrm{R}^{2}$ & 0.9998 \\
\hline${ }^{\mathrm{c}}$ Calibration curve & $\mathrm{Y}=46.32309 \mathrm{X}-14.93387$ \\
\hline Linear range $\left(\mu \mathrm{g} \mathrm{mL}^{-1}\right)$ & $1.563-100$ \\
\hline${ }^{\mathrm{d}} \mathrm{LOD}^{(\mu \mathrm{mLL}-1)}$ & 0.62 \\
\hline${ }^{ } \mathrm{LOQ}^{(\mu \mathrm{mL}-1)}$ & 1,89 \\
\hline
\end{tabular}

${ }^{a} \mathrm{RT}$ the retention time; ${ }^{b} \mathrm{R}^{2}$ regression coefficient of calibration curve $(n=7$, seven points); ${ }^{\mathrm{c}} \mathrm{Y}$, the peak area; $\mathrm{X}$ the concentration of standard compound; ${ }^{\mathrm{d}} \mathrm{LOD}$, the detection limit $(3.3 \mathrm{~S} / \sigma) ;{ }^{e} \mathrm{LOQ}$, the quantification limit $(10 \mathrm{~S} / \sigma) ; \mathrm{S}=$ standard deviation of low concentration, $\sigma=$ slope of the calibration line

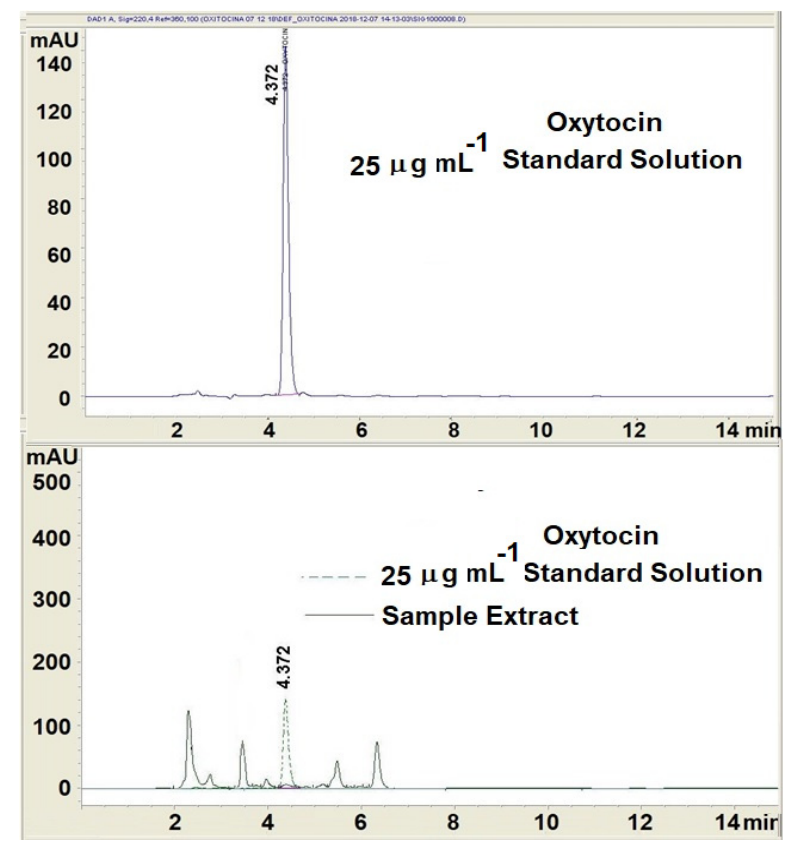

Figure 2. RP-HPLC chromatogram of $25 \mu \mathrm{gL}^{-1}$ Oxytocin standard solution and overlapped chromatograms of Oxytocin standard and sample solution. 
NOVEL POLYDIOXANONE - PLURONIC 127 OXYTOCIN IMPREGNATED MESH, PRELIMINARY STUDY OF OXYTOCIN RELEASE IN VITRO

The precision data are presented in Table 2 and the results show there were no significant differences between the test results. The method precision was satisfactory.

Table 2. Intra- and inter-day precision of Oxytocin

\begin{tabular}{|c|c|c|c|c|c|}
\hline \multirow{7}{*}{$\begin{array}{c}\text { Concentration } \\
\left(\mu \mathrm{g} \cdot \mathrm{mL}^{-1}\right)\end{array}$} & \multicolumn{2}{|c|}{$\begin{array}{c}\text { Intra-Day Precision } \\
(\mathrm{n}=6)\end{array}$} & \multicolumn{2}{c|}{$\begin{array}{c}\text { Inter-Day Precision } \\
(\mathrm{n}=9)\end{array}$} \\
\cline { 3 - 6 } & $\begin{array}{c}\text { Measured } \\
\text { concentration } \\
\text { Mean }^{\mathrm{a}} \pm \mathrm{SD}^{\mathrm{b}},\end{array}$ & $\begin{array}{c}\mathrm{RSD}^{\mathrm{c}} \\
(\%)\end{array}$ & $\begin{array}{c}\text { Measured } \\
\text { concentration } \\
\text { Mean }^{\mathrm{a}} \pm \mathrm{SD}^{\mathrm{b}},\end{array}$ & $\begin{array}{c}\mathrm{RSD}^{\mathrm{c}} \\
(\%)\end{array}$ \\
\hline \multirow{3}{*}{ Oxytocin } & 3.125 & $3.13 \pm 0.03$ & 1.04 & $3.12 \pm 0.12$ & 3.95 \\
\cline { 2 - 6 } & 12.5 & $12.48 \pm 0.14$ & 1.15 & $12.37 \pm 0.56$ & 4.56 \\
\cline { 2 - 6 } & 50 & $50.37 \pm 0.71$ & 1.41 & $49.88 \pm 2.13$ & 4.26 \\
\hline
\end{tabular}

${ }^{\mathrm{a}}$ Mean $=$ Average of $n$ determination; ${ }^{\mathrm{b}} \mathrm{SD}=$ Standard deviation;

${ }^{\mathrm{c}} \mathrm{RSD}=$ Relative standard deviation;

The result of Oxytocin release from the polimer sample matrix from the first day shows a quantity of $1.97 \mu \mathrm{g} \mathrm{mL}^{-1}$ Oxytocin extracted.

In the samples collected from the second, third and fourth day, the amount of Oxytocin released is below the detection limit of the method.

These results point out the strong bond betwen polydioxanone and Oxytocin, blocking the propper release of the hormone.

Preliminary results of Oxytocin release lead to hypotesis that to ensure a better release, probably an other compound like heparine, should be intercalated betwen this hormone and the polymer.

The surface morphology of polydioxanone - pluronic 127 - Oxytocin impregnated mesh was characterized by SEM and the results are shown in Figure 3.

SEM (Scanning Electron Microscopy) images shows a porous structure with specific geometric shapes and complex structures. Ceramic composite matrix, HA/TCP/Polymer, constitute the inorganic component of resorbable polymer/ceramic biocomposites. In this case, including calcium phosphates [e.g. calcium tetraphosphate $\left(\mathrm{Ca}_{4} \mathrm{P}_{2} \mathrm{O}_{9}\right)(\mathrm{CTP})$, tricalcium phosphate $\left[\mathrm{Ca}_{3}\left(\mathrm{PO}_{4}\right)_{2}\right.$, TCP], hydroxyapatite $\left[\mathrm{Ca}_{10}\left(\mathrm{PO}_{4}\right)_{6}(\mathrm{OH})_{2}, \mathrm{HA}\right]$, and their derivatives and combinations]], that are the most popular ceramics used in bone tissue engineering and controlled drug delivery systems, is benefic. 


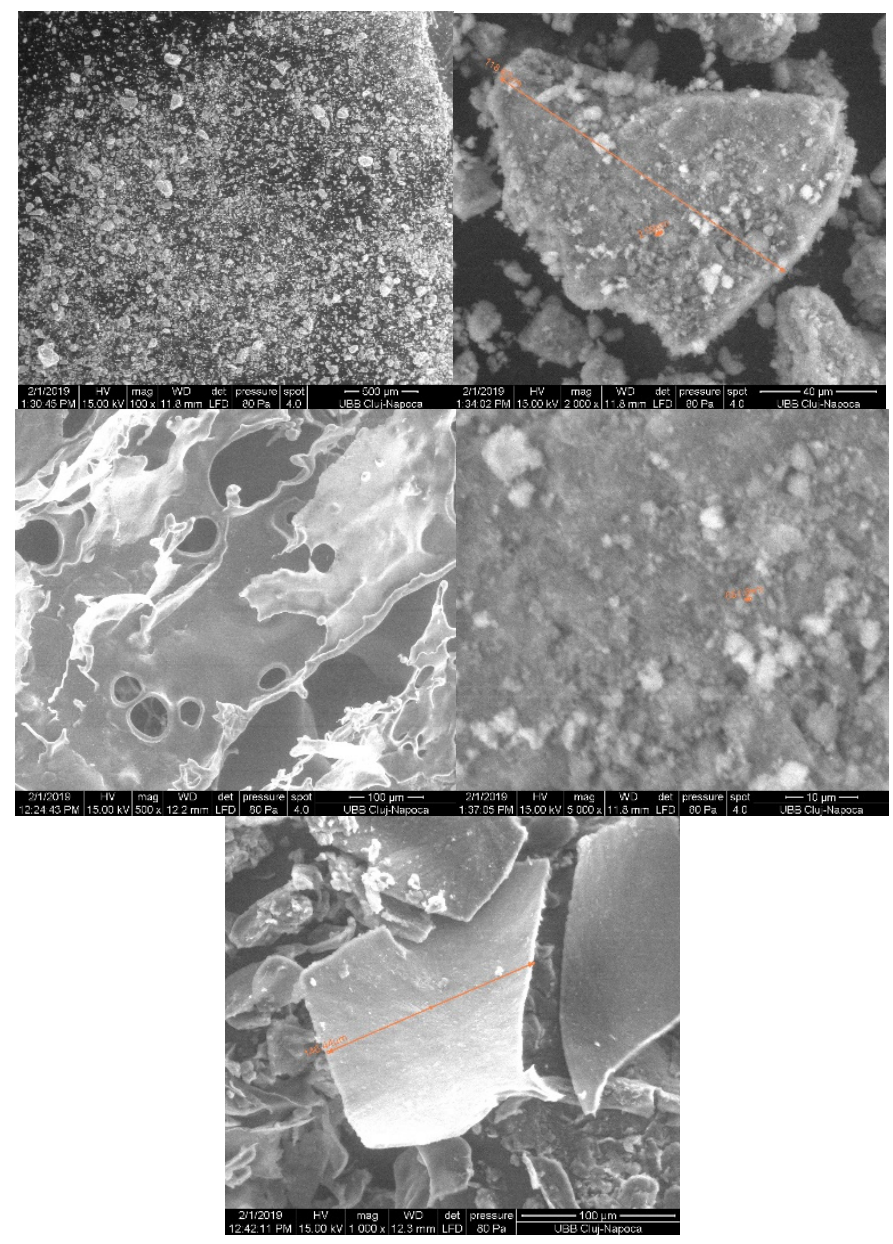

Figure 3. SEM imagine for polydioxanone - pluronic 127 mesh

\section{CONCLUSIONS}

Polydioxanone is a promising polymer for bone regeneration engineering. Its biocompatibility and polymorphism allow it to be fitted for every bone reconstruction need, from small defects characteristic for periodontal disease to large ones resulting from resective surgery or trauma.

To facilitate the continuous and controlled release of Oxytocin from the structure of new polymer, will be necessary to use (in future studies) a compound, like heparin, necessary to prevent the strong bonds with the other two primary components of the polymer. 
NOVEL POLYDIOXANONE - PLURONIC 127 OXYTOCIN IMPREGNATED MESH, PRELIMINARY STUDY OF OXYTOCIN RELEASE IN VITRO

Bioactive molecules play a critical role in bone gain by alloplastic grafts. Oxytocin presents a pleiade of metabolic effect that ensures osteoblastic activity boost and osteoclastic and bone adipocytes inhibition. The use of porous scaffolds is a potential method for repairing defects.

\section{EXPERIMENTAL SECTION}

\section{Chemical and reagents}

All reagents were of analytical grade. Analytical grade water was obtain from MilliQ Simplicity ultrapure water machine (Millipore, USA). Acetonitrile of HPLC grade and phosphoric acid were from (Optigrade Promochem, Germany). Oxytocin $1 \mathrm{mg}$ solid (Sigma Aldrich, Germany), $\mathrm{KH}_{2} \mathrm{PO}_{4}$ (Roanal, Budapest, Hungary), KOH pellets (Sigma Aldrich, Germany). Pluronic F127 (Sigma-Aldrich, Germany), ethyl acetate (Sigma-Aldrich, Germany), polydioxanone (Merck, Germany), Miglyol (Caesar \& Loretz, Hilden, Germany) hydroxyapatite and calcium triphosphate with chitosan (synthesis in ICCRR-UBB)

Pluronic-Polydioxanone mesh obtaining process: the preparation of the matrices was done by the interfacial deposition method. Two phases are prepared, the organic and the aqueous phase. The organic phase is composed of organic solvent (ethyl acetate) saturated with distilled water (2\%), polymer (polydioxanone), oil (Miglyol or mineral oil), hydroxyapatite and calcium triphosphate with chitosan. The aqueous phase is composed of distilled water saturated with organic solvent ( $2 \%$ ethyl acetate) and surfactant (Pluronic F127).

For both phases, the solutions are mixed, in order to obtain clear and homogeneous solutions, then the other precursors are gradually introduced, each in turn, after the introduced precursor is dissolved (for example the polymer, only to then polymerize around the oil droplets). After the two phases are prepared, the organic phase is introduced into the aqueous phase, this time instantly, but the aqueous phase is in the presence of $8000 \mathrm{rpm}$ rotation produced by Digital Dispenser T18-Agitator. Maintain the new solution for 10 minutes at this rotation, then add three or four times more water than the amount of solution resulting from the organic aqueous phase. This additional amount of water facilitates the diffusion of the respective surfactant of the organic solvent from the final solution.

These resulting solutions are then rotoevaporated and lyophilized, and the result are biocompatible mesh. 
ANDREEA ELENA MIRON (LUNGU), MARIOARA MOLDOVAN, DOINA PRODAN, MIHAELA VLASSA, MĂDĂLINA MOLDOVAN, RAREȘ CĂLIN ROMAN, MÎNDRA EUGENIA BADEA

\section{Oxytocin incorporation protocol and release determination}

The obtained meshes of polymer are immersed in $3 \mathrm{ml}$ Oxytocin saline solution and kept for 9 hours at $4^{\circ} \mathrm{C}$. The Oxytocin concentration in saline solution was $2.5 \mathrm{mg} \mathrm{mL}^{-1}$.

\section{Monitoring the Oxytocin content released from the meshes}

For the quantitative determination of Oxytocin released from the polymeric mesh, a liquid chromatographic RP-HPLC method with isocratic elution was used.

\section{Instrumentation and chromatographic conditions}

The Oxytocin determination were performed using an Agilent Technologies 1200 High Performance Liquid Chromatograph equipped with ALS G 1329 A autosampler, degasser G 1322 A, quaternary pump G 1311 A; thermostat TCC SL G 1316 B and diode array detector (DAD) G 1315 D. Data analyses were performed by ChemStation Software. The separation was achieved on a Phenomenex Luna 5u C18 100A, 250x4.6mm chromatographic column in isocratic conditions. The mobile phase was a mixture of acetonitrile: phosphate buffer $\mathrm{pH} 7(30: 70 \mathrm{v} / \mathrm{v})$, at a flow rate $1 \mathrm{ml} \mathrm{min}^{-1}$ and $30^{\circ} \mathrm{C}$ temperature of column thermostat. The injected volume was $50 \mu \mathrm{L}$ and chromatograms were collected at $\lambda=220 \mathrm{~nm}$ wavelength. The mobile phase is filtered and degassed through a $0.45 \mu \mathrm{m}$ nylon membrane filter (Nordic Chemicals, Romania).

An analytical balance Ohaus (Switzerland) were used for samples weighing. The phosphate buffer $\mathrm{pH}$ was measured with a Hanna $211 \mathrm{pH}-\mathrm{Metter}$ (Hanna Instruments, United Kingdom). IKA Dispersers T 18 digital ULTRATURRAX (IKA. Germany) for stirring the samples.

\section{Oxytocin standard solution preparation}

Oxytocin stock solution $\left(1 \mathrm{mg} \mathrm{mL}^{-1}\right)$ were prepared by dissolving the Oxytocin in PBS (Phosphate Buffered Saline) with $\mathrm{pH}$ 7. The solution was kept in the refrigerator at $4^{\circ} \mathrm{C}$ for one month period. The working standard solutions for the calibrating curve were prepared by the dilution of the concentrated stock solution in PBS. The calibration curve was obtained in the range of $1.563-$ $100 \mu \mathrm{g} \mathrm{mL}-1$ Oxytocin, each point on the curve being injected in triplicate.

\section{HPLC sample preparation}

The polymer pellets (polymeric mesh) with a diameter of $15 \mathrm{~mm}$ were placed in PVC vials with lids in $3 \mathrm{ml}$ of PBS extraction solution with $\mathrm{pH} 7$ and incubated at a temperature of $37^{\circ} \mathrm{C}$ for $24 \mathrm{~h}$. The extraction solutions were collected every 24 hours. The collected solutions were stored in the freezer $\left(-20^{\circ} \mathrm{C}\right)$ until their HPLC analysis, to determine the amount of Oxytocin released. 
NOVEL POLYDIOXANONE - PLURONIC 127 OXYTOCIN IMPREGNATED MESH, PRELIMINARY STUDY OF OXYTOCIN RELEASE IN VITRO

\section{Method validation}

For the quantitative determination of Oxytocin released from the polymeric mesh, were determined the following parameters: selectivity, linearity, LOD (limit of detection), LOQ (limit of quantification) and precision.

Selectivity was established by comparing the chromatogram of the Oxytocin standard solution with those of an Oxytocin sample extract. Linearity was established by plotting the analyte peak area against the analyte concentration. Calibration domain was between $1.563-100 \mu \mathrm{g} \mathrm{mL}^{-1}$

Parameter LOD was calculated based on Standard Deviation of the Response and the Slope of calibrating curve: $3.3 X S / \sigma$

Parameter LOQ was calculated based on the Standard Deviation of the Response and the Slope: The quantitation limit (QL) may be expressed as: $10 \mathrm{XS} / \sigma$

The intra-day and inter-day precision were expressed as percentage of relative standard deviation (\% RSD).

\section{ACKNOWLEDGMENTS}

This work was supported by a Grant of Romanian National Authority for Scientific Research \& Innovation, UEFISCDI, project number PN-III-P2-2.1-PED20192953, 334PED/2020.

\section{REFERENCES}

1. N. Goonoo, R. Jeetah, A. Bhaw-Luximon, D. Jhurry, Eur. J. Pharm. Biopharm., 2015, 97(Pt B), 371-391.

2. W.E. King III, Y. Gillespie, K. Gilbert, G.L. Bowlin, Polymers, 2019, 12, 1-17.

3. H. Tang, Z. Xu, X. Qin, B. Wu, L. Wu, X.W. Zhao, Y. Li, Biomaterials, 2009, 30, 3224-3233.

4. A. Ahmed, C. Gibson, P. Ayliffe, Br. J. Oral Maxillofac. Surg., 2013, 51,197-198.

5. T.H. Kim, S.H. Oh, S.Y. Chun, J.H. Lee, J. Biomed. Mater. Res. A, 2014, 102, 1264-1274.

6. J.H. Lee, S.-W. Kim, U.-K. Kim, S.H. Oh, S. June-Kim, B.-W. Park, J.-H. Kim, Y.-S. Hah, D.R. Kim, G.-J. Rho, G.-H. Maeng, R.-H. Jeon, H.-C. Lee, J.-R. Kim, G.-C. Kim, J.-H. Byun, J. Biomed. Mater. Res. A, 2013, 1, 942-953.

7. J.H. Lee, J.H. Kim, S.-H. Oh, S.-J. Kim, Y.-S. Hah, B.-W. Park, D.R. Kim, G.-J. Rho, G.-H. Maeng, R.-H. Jeon, H.-C. Lee, J.-R. Kim, G.-C. Kim, U.-K. Kim, J.H. Byun, Biomaterials, 2011, 32, 5033-5045. 
ANDREEA ELENA MIRON (LUNGU), MARIOARA MOLDOVAN, DOINA PRODAN, MIHAELA VLASSA, MĂDĂLINA MOLDOVAN, RAREȘ CĂLIN ROMAN, MÎNDRA EUGENIA BADEA

8. J.H. Lee, Y.S. Hah, H.Y. Cho, J.H. Kim, S.H. Oh, B.W. Park, Y.H. Kang, M.J. Choi, J.K. Shin, G.J. Rho, R.H. Jeon, H.C. Lee, G.C. Kim, U.K. Kim, J.R. Kim, C.I. Lee, J.H. Byun, Tissue Eng. Part A., 2014, 20, 940-953.

9. I.M. Diniz, C. Chen, X. Xu, S. Ansari, H.H. Zadeh, M. M. Marques, S. Shi, A. Moshaverini, J. Mater. Sci. Mater. Med., 2015, 26,153.

10. H. Wu, Y. Deng, Y. Yan, D. Quan, Si M, Sheng Wu Yi Xue Gong Cheng Xue Za Zhi., 2011, 28, 1148-1153.

11. A.S. Akay, V. Arısan, E. Cevher, M. Sessevmez, B. Cam, J. Orthop. Res., 2020, 38, 1676-1687.

12. J.W. Park, J.M. Kim, H.J. Lee, S.H. Jeong, J.Y. Suh, T. Hanawa, J. Clin. Periodontol., 2014, 41,181-190.

13. M. Wang, L. Lan, T. Li, J. Li, Y. Li, Connect. Tissue Res., 2016, 57, 220-225.

14. A. Szeto, P.M. McCabe, D.A. Nation, B.A. Tabak, M.A. Rossetti, M.E. McCullough, N. Schneiderman, A.J. Mendez, Psychosom. Med., 2011, 73, 393-400.

15. D. Ashenafi, E. Van Hemelrijck, S. Chopra, J. Hoogmartens, E. Adams, J. Pharm. Biomed. Anal., 2010, 51, 24-29.

16. M. Mishra, S. Ali, M. Das, Toxicol. Mech. Methods, 2014, 24, 342-346.

17. M.A. Kukucka, H.P. Misra, J. Chromatogr. B, 1994, 653, 139-145.

18. G. Zhang, Y. Zhang, D.M. Fast, Z. Lin, R. Steenwyk, Anal. Biochem., 2011, 416, 45-52.

19. O.S. Mabrouk, R.T. Kennedy, J. Neurosci. Methods, 2012, 209, 127-133

20. E. Moriyama, H. Kataoka, Chromatography, 2015, 2, 382-391. 